\title{
Author Spotlight: Mohammad Bilal
}

\section{Mohammad Bilal $^{1}$}

Published online: 5 May 2020

(c) Springer Science+Business Media, LLC, part of Springer Nature 2020

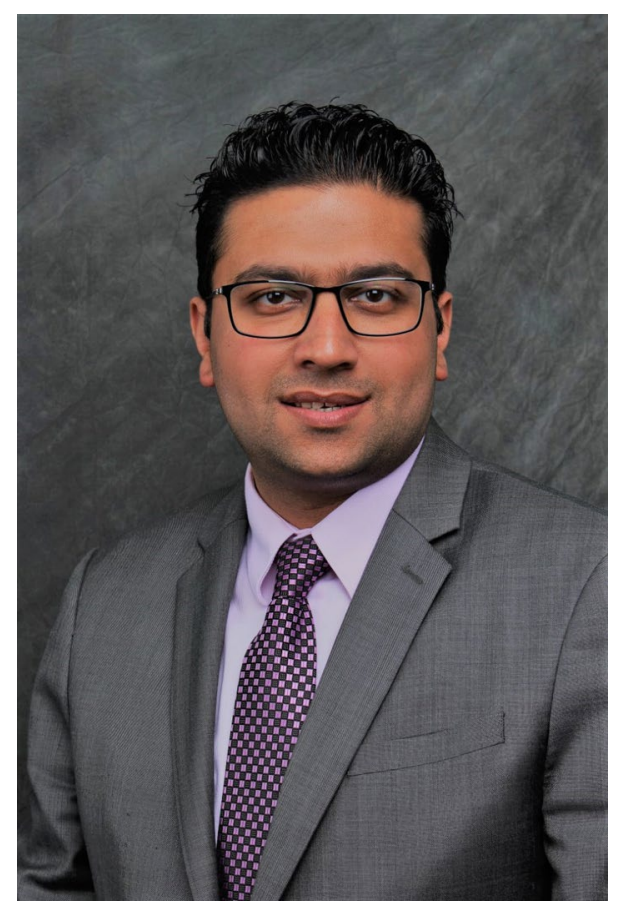

Medical School. He graduated from Army Medical College in Pakistan and subsequently joined Allegheny Health Network in Pittsburgh for his internal medicine residency. He completed his gastroenterology fellowship at the University of Texas Medical Branch at Galveston, where he also served as the chief gastroenterology fellow. His research interests focus on advanced endoscopy techniques, pancreatobiliary diseases and colon cancer. He is also passionate about medical education and completed a "Scholars in Education" program during his fellowship. He plans to continue a career in academic gastroenterology and advanced endoscopy after graduating his fellowship.

Publisher's Note Springer Nature remains neutral with regard to jurisdictional claims in published maps and institutional affiliations.

Mohammad Bilal, MD is an advanced endoscopy fellow at the Beth Israel Deaconess Medical Center with Harvard

Mohammad Bilal

billa17@hotmail.com

1 Center for Advanced Endoscopy, Division of Gastroenterology, Beth Israel Deaconess Medical Center, Harvard Medical School, Boston, MA, USA 